\title{
A FLOR NO BUTOH DE KAZUO OHNO
}

Felicia Megumi Ogawa

Marido e mulher, no céu, transformam-se em um anjo

Emanuel Swedenborg

RESUMO: Trata-se de um estudo comparativo sobre as linguagens Butoh $\mathrm{e}$ Nô, focalizando o aspecto da interpretação do ator. Os conselhos de Zeami, dirigidos aos atores do teatro Nô, registrados no Livro III do Fûshikaden (tratado sobre o teatro Nô, escrito no século $\mathrm{XV}$ ), serviram como base. Zeami enfatiza a necessidade de os atores polirem incansavelmente sua arte a fim de cativar o coração do público. Fato que só se torna possível aos que conseguirem captar a Flor da interpretação. A análise da interpretação e do pensamento de Kazuo Ohno, nascido em 1906, um dos fundadores da linguagem Butoh e ainda atuante nos palcos do mundo, é a referência para a comparação das duas linguagens. Assim, a busca da Flor de Zeami no universo da arte de Kazuo Ohno foi o fio de Ariadne no labirinto do Butoh.

RESUME: The article is a comparative study about Butoh and Nô language, focusing on the aspect of an actor's performance. Zeami's advice given to the actors of Nô theatre, recorded in Fûshikaden - Book III (written in the XV century) served as the base. Zeami stresses the necessity of actors tirelessly polishing their art, in order to captivate the spectators. Something which is only possible when the actors get to apprehend the Flower of interpretation. The analyses of the performance and thoughts of Kazuo Ohno, born in 1906, one of the founders of Butoh's Language and still acting at present on the stages around the world is the reference of the comparison among two languages. Thus the search for Zeami's Flower in the universe of Ohno's art is the Ariadne's thread in the Butoh labyrinth. 
PALAVRAS-CHAVE: Nô, Butoh, Flor, Evanescência, Aprendizado

KEYWORDS: No, Butoh, Flower, Evanescense, Apprenticeship

Fûshikaden (Da Transmissão da Flor de Interpretação) foi o primeiro dos tratados teatrais legados por Zeami - ator e teórico do teatro Nô - à posteridade. Escrito no século XV ao longo dos anos 1400 a 1418, é considerado o mais antigo documento do gênero no Japão. Composto por sete livros, contém as transcrições dos ensinamentos de seu pai Kan'ami a respeito de conceitos teatrais do Sarugaku, como era conhecido o teatro Nô na época. No entanto, como observa Sakae Murakami Giroux, esse trabalho foi redigido muito após a morte de Kan'ami, e por isso "talvez fosse mais exato considerar que Zeami nele exprime de que forma apreendeu e interpretou as idéias de seu pai"!

Com base em algumas das idéias expostas sobre a flor no Fûshikaden, é minha intenção fazer uma leitura dos conceitos do Butoh, linguagem artística corporal nascida no pós-guerra, estabelecendo correlações entre as duas expressões cênicas. Pois, apesar do Fûshikaden estar distante mais de 500 anos do surgimento do Butoh (fins dos anos 50 ), as idéias nele contidas não perdem em nenhum momento a atualidade. $E$, por outro lado, é patente o fato de que, cada vez mais, o contemporâneo busca suas raízes ancestrais, como acontece com o Butoh.

Este estudo vai se apoiar principalmente nos conceitos contidos no Livro III, onde Zeami focaliza o comportamento do ator, orientando-o, advertindo-o para polir sua arte com a finalidade de cativar o coração do público. Zeami concentra todas as idéias simbolicamente na flor que, segundo ele, é a imagem do Belo que suscita o sentimento do espectador através da linguagem da representação. No entanto, Giroux ressalta que, nos tratados, Zeami fornece explicações não sobre o Belo da flor, mas sobre os meios e as maneiras de expressar esta flor, técnica que o ator deve dominar, conhecendo de antemão a flor que sensibiliza o público ${ }^{2}$.

O enfoque sobre o ator pareceu-me ser procedente, pois no Butoh tudo se concentra no corpo, elemento-chave dessa linguagem artística e também o único com existência concreta. Através dele, o ator procura traduzir seu mundo interior. Consequientemente, espera-se, nessa busca, que ele seja não apenas o representante de uma arte, mas a própria arte.

Por isso, para Eric Seland, estudioso das artes japonesas, o Butoh não é passível de interpretação, como por exemplo o haikai. Assim, os críticos dessa arte se limitam a selecionar, organizar em categorias e listar determinadas características e posturas do ator, que possam servir de guia genérico para a compreensão de sua linguagem. Seland compara tais anotações com as do Kadensho (como é também chamado o Fûshikaden). Afirma ser o Kadensho a "Bíblia do Ator", cujos ensinamentos, ao longo dos anos, vêm sendo alternadamente ignorados ou respeitados, exatamente como a própria Bíblia. Atualmente, ainda segundo Seland, a arte de Kazuo Ohno, um dos fundadores do Butoh, é a que melhor sintetiza a essência do Kadensho ${ }^{3}$

1. Sakae Murakami Giroux, Zeami: Cena e Pensamento Nô, São Paulo, Perspectiva, 1991, p. 105.

2. Idem, p. 107.

3. Eric Seland, "Retorno à Essência", in Kazuo Ohno Butoh-fu, Tóquio, ed. Shisho-sha, 1989. 
Assim, buscar a flor de Zeami no universo da arte de Kazuo Ohno será o fio de Ariadne no labirinto do Butoh.

\section{A Flor e a Evanescência}

No Livro III do Kadensho, Zeami fala a respeito da "interpretação da flor evanescente" do ator. Zeami acha quase impossível descrevê-la em palavras. É um estágio do aperfeiçoamento do ator, ao qual não se chega apenas através do acúmulo de ensaios e domínio técnico, mas sim a partir do momento em que ele incorpora verdadeiramente a essência da flor. Só então ele poderá alcançar a interpretação da flor evanescente. Isso nos leva a crer que esse estado é captado em um nível superior ao da própria flor, mas, evidentemente, sem a existência da flor não há o estado de evanescência ${ }^{4}$

Pode-se deduzir, ainda, que o ator só chegará à interpretação da flor evanescente com o amadurecimento de sua arte e de seu universo interior, e, conseqüentemente, com o avanço da idade. Mas, isso também não basta, ensina Zeami: "Aquele que tem um bom domínio técnico e é famoso, mas não pesquisou adequadamente a flor, poderá manter a fama, mas não poderá manter a flor até a velhice. Aquele que conseguiu captar verdadeiramente a flor, ainda que sua capacidade técnica diminua, a flor permanecerá com ele. E assim sua arte continuará sempre interessante ${ }^{5}$. Conclui-se, portanto, que a interpretação da flor evanescente é a soma da compreensão da flor mais a maturidade interior e cronológica do ator.

No entanto, se o ator só atinge a maturidade da sua arte quando já perdeu a juventude, e considerando-se que o envelhecimento do corpo - que no Butoh se confunde com a própria arte - é uma realidade inexorável, como ele poderá atingir o estado da flor evanescente? Esta questão é colocada pelo crítico Tatsuo Ishii, para quem inexiste teoria ou teórico teatral, da antigüidade a nossos tempos, que tenha encarado de frente a questão da velhice do ator (não há registro de alguém que o tenha feito, de Aristóteles, na antiga Grécia, passando pela teoria teatral em sânscrito, na Índia; por Stanislawski, na Rússia; Artaud, na França; Brecht, na Alemanha e Grotowski na Polônia). Ishii ressalta que nas artes tradicionais como o Nô, o ator deve começar seu aprendizado na mais tenra idade, mas só aos 40 ou 50 anos pode se considerar maduró.

Como resolver o impasse? É o próprio Ishii quem aponta para a possibilidade da solução, com base em um exemplo concreto: Kazuo Ohno. Na sua opinião, no Butoh de Ohno é possível sentir o estado de evanescência.

No espetáculo Suiren, de Monet, por exemplo, ele não só restaurou a idéia da interpretação de um velho no palco, mas ainda a transformou em aspecto positivo, dando a impressão de ter revelado um caminho para esta questão ${ }^{7}$

4. Akira Omote e Shuichi Katô, "Zeami Zenchiku", in Nihon Shisô Taikei, tomo 24, Tokyo, Iwanami Shoten, 1974, pp. 35 e 36.

5. Idem, pp. 31 e 32.

6. Tatsuo Ishii, “A Velhice e a Dança”, in Kazuo Ohno Butô-fu, Tokyo, ed. Shisho-sha, 1989, p. 318.

7. Idem, ibidem. 
E acrescenta: "Na arte de Kazuo Ohno existe tanto a flor como a evanescência"8.

Descrevendo a apresentação do ator em O Mar Morto, em Rimini (1985), Leonetta Bentivoglio mostra também o fascínio que Ohno exerce no palco, resolvendo com extrema pureza a questão da velhice:

No espetáculo, Kazuo se transforma em "larva" amassada e suntuosa [...] Nos travestimentos femininos, passa do faustoso ao absurdo: jovem casta, princesa virginal, dançarina líbero-floreal [...], amassado e sinistro. Gestos mímicos destilados, pequenos passos torcidos. Mãos firmes e longas que falam, membros que se arrastam e que vibram de emoções. Uma intensidade dramática e irreverente. Uma máscara fúnebre que olha desesperadamente a vida. É uma dança que se transforma em morte e velhice, comovente senso de corrupção do corpo. Espelho de um insustentável peso do ser. Uma dança que é uma "loucura" e estranho sonho de uma feminilidade agoniada e que não dá para alcançar (procurada mas não alcançada) revisitada por um estranho corpo de um velho que parece ser o mais antigo do mundo [...] No final, aclamado com vários buquês de flores, é aplaudidíssimo. Satisfeito e entupido do misticismo que transborda do espetáculo, o público presta-lhe homenagem. Repetidas mesuras femininas e sorrisos. O mestre sai de cena como um magnifíco pesadelo que se dissipa?.

Bentivoglio não estabelece ligação entre a interpretação do ator e a da flor evanescente, mas sem dúvida o fascínio que Kazuo exerceu sobre ela e a platéia é a evidência de que sua arte alcançou aquele estágio.

Kazuo Ohno, por seu lado, demonstra claramente sua admiração e concordância em relação aos conceitos de Zeami sobre a flor evanescente. Isso fica evidente em um texto de sua autoria, cujo título é "A Flor e a Evanescência", onde descreve a sua profunda emoção diante da imagem de um velho cavalo, que ilustrava a capa de uma publicação exposta na vitrine de uma livraria em Dresden ${ }^{10}$.

Percebe-se, no texto, que Ohno sobrepõe sua própria imagem à do cavalo, ressaltando o olhar vivo e ao mesmo tempo tranqüilo do animal, ainda que em corpo esquelético, abraçado à morte. Aos olhos do artista, o cavalo se transforma em uma visão fantástica, surgida de uma antiga era, anterior a Cristo" ${ }^{11}$. Descreve ele:

A cabeça abaixada, o focinho voltado para dentro, ele parecia observar a si mesmo, enquanto se expunha ao olhar de outrem. Parecia revelar o universo interior do velho que dividia com ele a imagem [...] Não pode ser só enquanto há vida, deve continuar mesmo no momento da morte. $\mathrm{Na}$ hora da morte também, exclamei, dentro da vitrine em Dresden. A alma que parecia ter sido sugada por aquele cavalo, estava transformada dentro de mim $^{12}$.

Tatsuo Ishii acredita na existência de uma estética que seja domínio exclusivo dos atores que atingem a velhice. Embora neles a cor e o viço do rosto desapareçam e os movimentos não sejam os mesmos da juventude, o Belo permanece, como resultado de algo acumulado durante a vida inteira, com imparcialidade, sem expectativas. E é como

8. Idem, p. 319.

9. Bentivoglio Leonetta, in La Republica Spectacoli, Milão, 1985.

10. Kazuo Ohno, "A Flor e a Evanescência", in Kazuo Ohno Butô-fu, Tóquio, ed. Shisho-sha, 1989, p. 198.

11. Idem, ibidem.

12. Idem, pp. 199 e 200. 
se todo esse universo fosse absorvido por um coração grandioso, capaz de sobrepujar todas as técnicas. No entanto, como adverte Zeami, é preciso que o ator, mesmo depois de velho, não abandone a pureza de coração de um iniciante. Nesse aspecto, um bom exemplo é novamente Kazuo Ohno, nas palavras de Tatsuo Ishii: "Mesmo depois de velho, ele mantém o frescor de quem se relaciona com a arte pela primeira vez... Isso porque a vida humana é finita, enquanto a arte não tem fim"'13.

Não esquecer a pureza virginal, na velhice, significa entender que a vida humana tem seu fim, enquanto o Nô é eterno. (in Zeami - Kakyô)

\section{A Flor}

Qual seria para Zeami o significado da verdadeira flor, e como o ator poderia captá-lo?

Na linguagem teatral do $N o ̂$, a flor seria o efeito cênico da representação ou, em outras palavras, o impacto emocional transmitido pelo trabalho do ator. E esta flor é captada primeiramente pelo espectador como a essência do belo... "O belo da flor que se reflete nos olhos do público e a alma da flor que nasce do sentimento do ator formam o verso e o reverso de uma mesma flor"14

Do mesmo modo, a flor do Butoh é a própria alma do artista, e, para que ela seja verdadeira, o ator não pode prescindir da semente, que é todo o processo de aprendizagem desenvolvido durante sua vida - um aprendizado que não se limita às técnicas corporais, ao domínio de variadas linguagens ou ao mero acúmulo de conhecimentos. O essencial é que ele desenvolva a sabedoria, depurando atos e pensamentos, o que significa depurar a própria arte. A flor está ligada à alma, ao coração, e a semente ao conhecimento das técnicas ${ }^{15}$.

Zeami chama a atenção para um aspecto muito importante nessa busca da flor: "O ator nunca deve pensar que essa tarefa seja trabalhosa e maçante" ${ }^{16}$. $O$ artista, para ser pleno, deve se colocar por inteiro no processo de criação e sentir prazer no ato criativo. E nessa busca, que deve ser permanente, é importante que ele mantenha uma postura de humildade diante do aprendizado. Por isso, Zeami alerta os atores mais experientes para que procurem aprender mesmo com os principiantes e atores menos hábeis. Pois o próprio orgulho que rejeita esse aprendizado acaba aprisionando o artista, impedindo-o de encontrar o seu verdadeiro Nô - para Zeami, sinônimo da verdadeira flor: "A flor representa, de fato, a vida do Nô, e conhecê-la significa atingir os arcanos do caminho desta arte"17

Para se atingir a flor, a semente deve ser plantada bem cedo - aos sete anos, segundo Zeami. O futuro ator precisa obter o domínio de várias técnicas, além de uma

13. Tatsuo Ishii, op. "̄it., p. 320.

14. Sakae Murakami Giroux, op. cit., pp. 106 e 107.

15. Akira Omote e Shuichi Katô, op. cit., pp. 34 e 35.

16. Idem, pp. 36 e 37.

17. Idem, pp. 32 e 34 . 


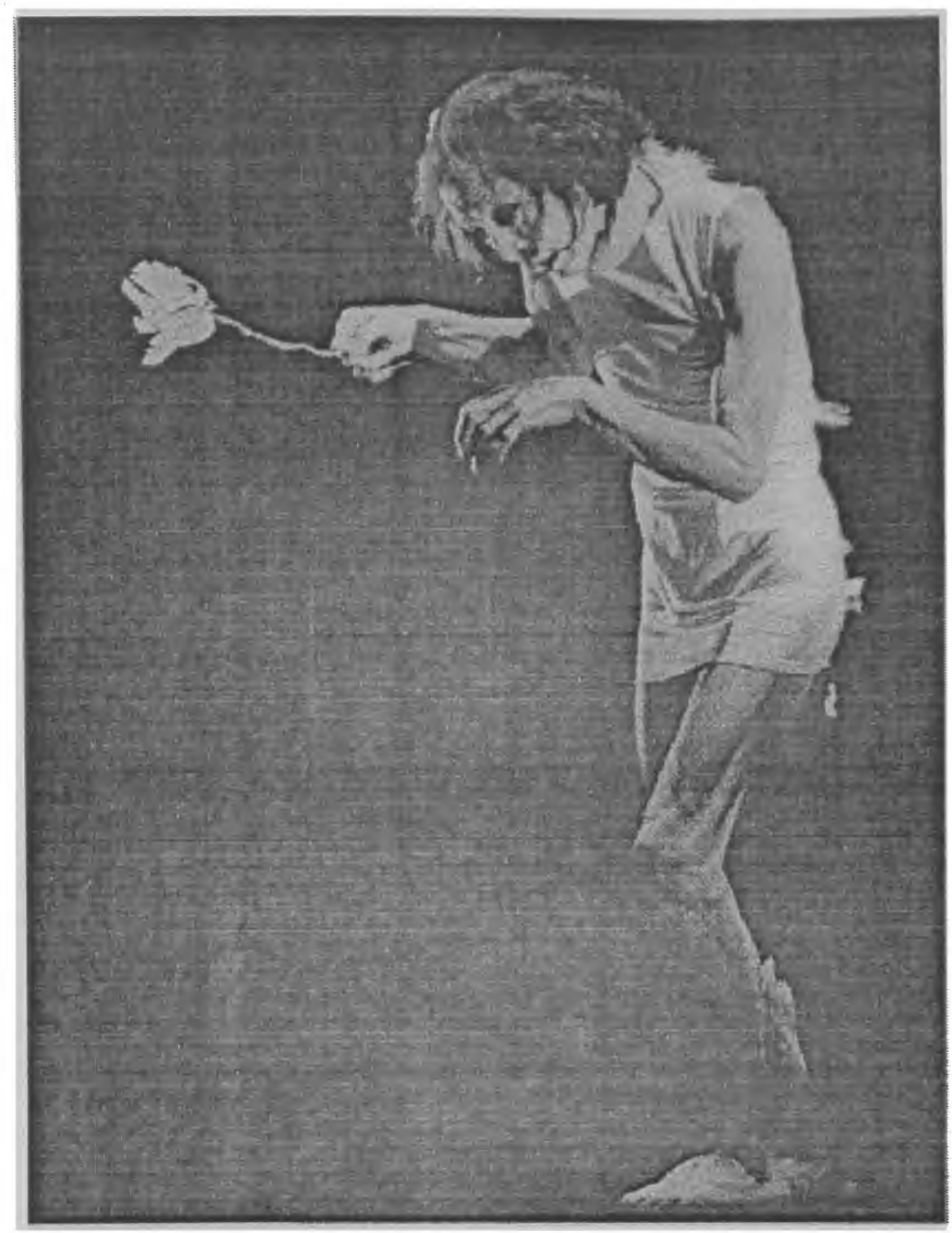

Kazuo Ohno. "A Flor e a Evanescência" no espetáculo Minha Mãe. 


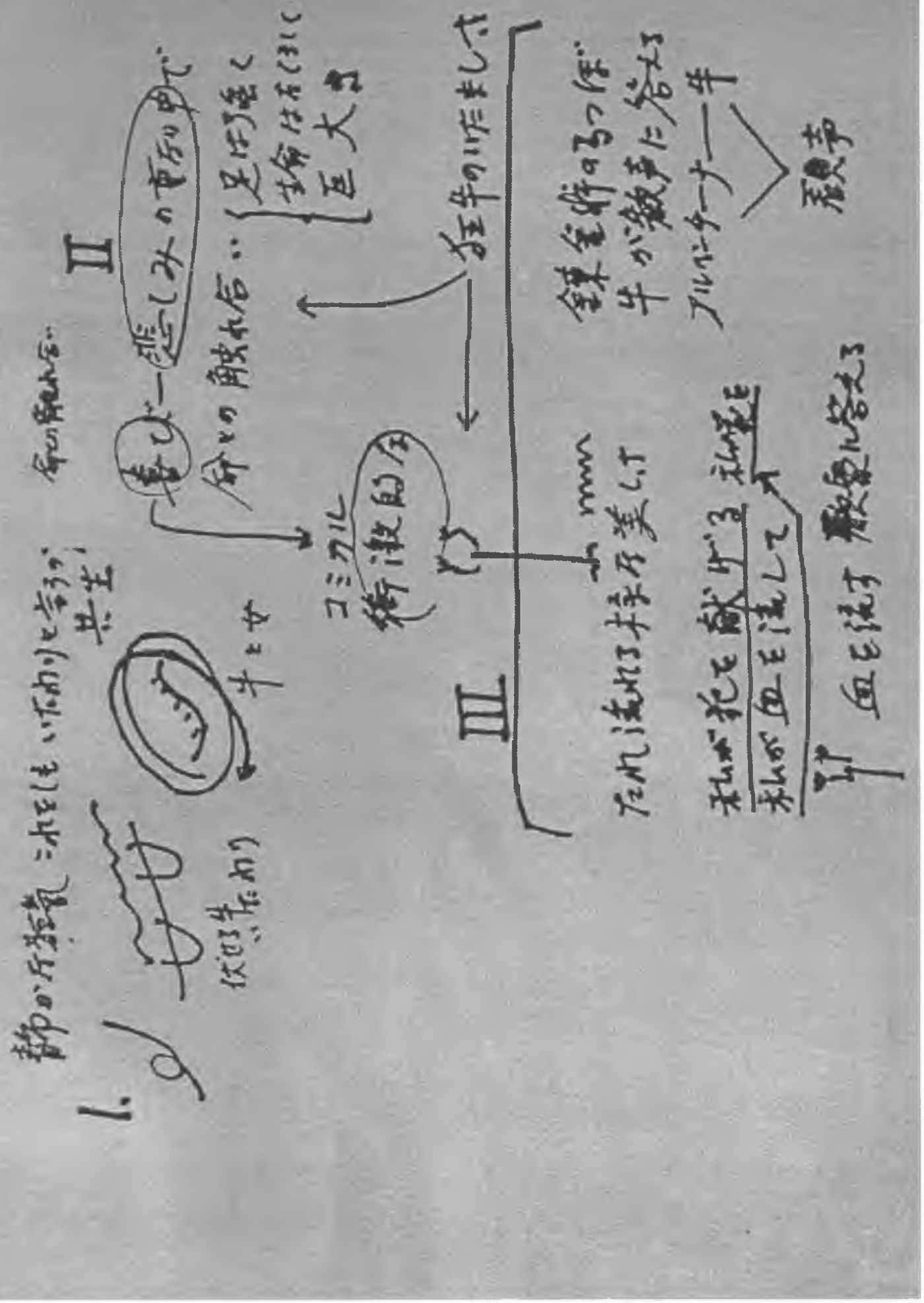

ป 


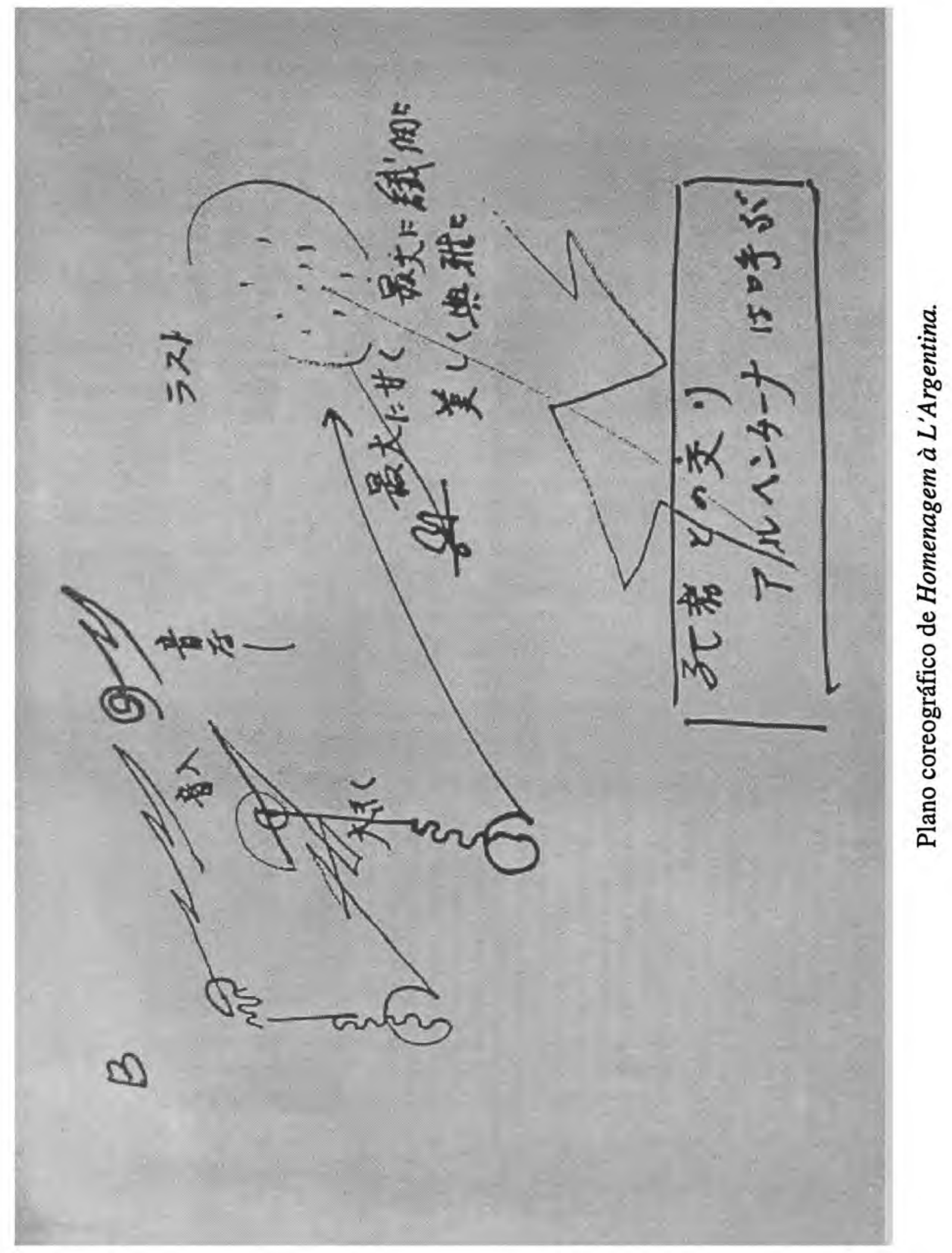


profunda compreensão das mímicas, registrando-as no fundo do coração. Kazuo Ohno diz que, no Butoh, essa primeira etapa leva pelo menos cinco anos e deve começar pela observação dos movimentos cotidianos do corpo.

Durante esse período [continua o mestre], $o$ aprendizado se realiza embasado não se sabe se na constante conscientização da análise e síntese dos movimentos do próprio corpo, ou se no aprofundamento do conhecimento sobre a vida, ou em ambos ou, ainda, em nenhuma dessas hipóteses. A sabedoria de viver, o respeito à própria vida e à de outros, o reconhecimento da Natureza, são temas que vão surgindo no processo do aprendizado. As dores de uma existência ou então seus prazeres, os ferimentos que marcam nossas vidas, as dádivas da Natureza e sua destruição são, para mim, fenômenos especialmente caros.

No entanto, há coisas no Butoh que não é possível ensinar, diz Ohno. E explica:

Suponhamos que estivéssemos em uma aula onde o tema fosse o "Pai Nosso". Cada um de vocês tentaria se expressar através do corpo, usando os movimentos que o tema lhes inspiraria. E eu os compreenderia todos, por menores que fossem os gestos. Mas, o problema começa aí. Para mim, dançar, com o único objetivo de fazer os outros entenderem as imagens que o tema evoca é apenas uma questão anterior ao Butoh. O importante é vocês expressarem suas posturas diante da vida, os sentimentos que decorrem do fato de se viver as verdades contidas no "Pai Nosso". Igualmente importante é reconhecer a própria seriedade do viver, bem como a maneira como vocês vão se confrontar com essa questāo. E, sobre isso, nada posso lhes ensinar. É preciso que cada um faça uma reflexão. Em minha opinião, vocês devem procurar, no Butoh, uma oportunidade para travar um duelo consciente com o solene ato de viver ${ }^{18}$.

\section{A Flor, o interessante e o insólito}

Se a flor é a emoção que o trabalho do ator provoca no público, gerando nele os mais variados sentimentos, quais as condições para que ela se manifeste? Em primeiro lugar, obviamente, é preciso que o espetáculo seja interessante. E, para Zeami, o que mais atrai as pessoas é o insólito. No entanto, a intenção do artista de passar o insólito não deve ser percebida, caso contrário o espetáculo deixa de ser interessante. Segundo Zeami, é preciso agir de modo inverso às expectativas do público, enganar a sua expectativa. E essa estratégia pode ser a semente do insólito.

Kôi Nagata, haicaísta, hoje com 97 anos de idade, viu como a aplicação prática dessa teoria a interpretação de Kazuo Ohno no Suiren, de Monet. Diante da observação de que o espetáculo parecia caracterizar-se pela pouca movimentação, Ohno respondeu:

É verdade. Ele ainda está em processo de criação. Mas, a verdade é que, de alguns anos para cá, tenho refletido muito a respeito do fato de que de nada adianta movimentar-se muito. Embora o movimento seja necessário, existem com certeza movimentos interiores. Trata-se, portanto, de reduzir os movimentos visíveis e se aquietar, aguardando com paciência que o interior se manifeste.

18. Kazuo Ohno, "Palavras de Aprendizagem do Butoh", in Minha Mãe, ed. Ohno Kazuo Kenkyu-jô, p. 1. 
Nagata relaciona essa postura de Ohno, com a questão do interessante de Zeami ${ }^{19}$.

Como a ausência de movimento em um espetáculo pode ser interessante? $\mathrm{Na}$ interpretação de Ohno, Nagata observou que o não movimento ocorre nos espaços entre determinadas ações. Como a da mão que, "dançando" pára subitamente no ar; ou da canção que cessa, deixando lugar ao silêncio. No entanto, a atuação extremamente concentrada do dançarino faz perdurar a tensão criada pelo gesto ou pelo som interrompido. É como se, naquele momento, todo seu universo interior se manifestasse e fosse preenchendo o espaço vazio até chegar à ação subsequiente. E esses momentos, em que só a alma do artista parece falar, são os que mais despertam o interesse ${ }^{20}$.

\section{A Flor, o Texto e a Alma}

Para um ator ter um bom desempenho, Zeami considera fundamental que ele crie seu próprio texto ${ }^{21}$. Isso lhe permitirá representar completamente à vontade. E é o que Kazuo Ohno faz. A maioria dos textos que interpreta são de sua própria autoria. É hábito seu registrar minunciosamente, todas as manhãs, os fatos que o tenham emocionado. Sua postura no processo criativo baseia-se, portanto, nos eventos cotidianos. Seus planos coreográficos, embora às vezes possam parecer improvisados, são rigorosamente calculados ${ }^{22}$

Ohno afirma que, já na sua preparação para entrar no palco, enquanto se processa sua metamorfose física através do aquecimento do corpo, preparação dos cabelos, pintura do corpo e do rosto, ele experimenta também uma transformação espiritual, em sua opinião, fundamental para o trabalho do artista. Nesses momentos, e mesmo durante a apresentação, ele diz receber a visita de inúmeras almas:

No instante em que pisei no palco, em Buenos Aires, entre os mais de mil espectadores na platéia muitos mortos ocupavam os espaços, olhando para mim. Foi-me ensinado que vivemos porque recebemos a graça de inúmeros mortos. Mesmo em relação à minha dança. É um aburdo pensar que foi criada por mim. É apenas uma tentativa de expressar a minha prece aos antepassados e às almas que assistem a mim na platéia ${ }^{23}$

\section{A Flor de "La Argentina" fez nascer a dança de Kazuo Ohno}

O Butoh, hoje conhecido em quase todo o mundo, nasceu do fascínio que a flor da dançarina Antônia Mercê provocou em Kazuo Ohno, durante uma apresentação que ela fez, em 1929, no Teatro Imperial de Tóquio. "La Argentina" como era conhecida, tinha uma formação de balé clássico, e sua performance no palco era o resultado de uma personalidade intuitiva, de alguma experiência no teatro e do conhecimento das

19. Kôi Nagata, "Ohno Kazuo e Zeami", in Ohno Kazuo Butoh-fu, Tóquio, ed. Shinsho-sha, 1989, p. 313.

20. Idem, p. 313.

21. Akira Omote e Shuichi Katô, op. cit., p. 30.

22. Anexamos duas cópias do plano coreográfico.

23. Kôi Nagata, op. cit., p. 313. 
danças espanholas tradicionais. Ela também se destacou por dar ao flamenco, até então apenas uma dança folclórica local, uma linguagem universal.

Naquela primeira e única vez em que Kazuo Ohno assistiu à apresentação de Antônia Mercê, sentiu que a sua dança "atraía as pessoas para um mar de excitação, ela encarnava a dança, a literatura, a música e a arte, e além disso apresentava o amor e a dor da vida real" O deslumbramento de Ohno aparece também em outro comentário que fez sobre o espetáculo:

A genealogia de sua alma encantadora, marcada por várias impressões, era exposta e subseqüentemente desaparecia em sua dança. Quando relembro a excitação provocada por "La Argentina" no palco, posso declarar com felicidade que foi a dança de uma criatura que tomou parte na criação do Céu e da Terra.

Também ficou gravada em Ohno uma frase de "La Argentina": "Não foi a minha arte que comoveu as pessoas. Eu simplesmente recebi todas as coisas que me comoveram e tentei passar para vocês"

Foi em 1977, aos 71 anos que, finalmente, Ohno materializou seus sentimentos, criando o espetáculo Homenagem à L'Argentina, que fez a sua flor eclodir e se revelar ao mundo. E, ao longo dos últimos 20 anos, ele vem transmitindo a flor evanescente de Zeami. 